\title{
A study on the time constant for an impulse sound level meter (A study on the loudness of impact sound. V)
}

\author{
Masazumi Kumagai,* Yōiti Suzuki, ** and Toshio Sone** \\ * Sendai Radio Technical College, \\ Miyagi-cho, Miyagi, 989-31 Japan \\ ** Research Institute of Electrical Communication, \\ Tohoku University, \\ Katahira, Sendai, Miyagi, 980 Japan
}

(Received 5 October 1983)

\begin{abstract}
Some experiments on the loudness of impact sound were carried out, where the model impact sounds based on the actual ones were used as test stimuli. From these experiments, it is clarified that the reading of the sound pressure level through a circuit with a certain time constant can well describe the loudness of impact sounds than its sound energy does. The values of the time constant of exponential averaging circuit are investigated, accordingly. As the results of this study, a sound level meter with two exponential averaging circuits, one of which has $5 \mathrm{~ms}$ rise time constant and $250 \mathrm{~ms}$ decay time constant, and the other has $125 \mathrm{~ms}$ rise time constant and $250 \mathrm{~ms}$ decay time constant, shows a good agreement with loudness of a single or repeated impact sounds in the same way as in the loudness of steady sound.
\end{abstract}

PACS number: 43. 66. Cb, 43. 85. Fm

\section{INTRODUCTION}

Several psycho-acoustical experiments on loudness of impact sounds were carried out, in which the model impact sounds determined on the basis of a wide investigation of actual ones were used as the stimuli. ${ }^{1-4)}$ Those stimuli were synthesized by amplitude modulation of sinusoidal carrier (500, 1000 or $2000 \mathrm{~Hz}$ ), pink noise or white noise. The point of subjective equality (PSE) for loudness of impact sound was obtained in an anechoic room by the method of adjustment, and stimuli were presented through a loudspeaker.

Two examples of the results are shown in Fig. $1^{2,3)}$ and Fig. 2.4) As seen from these figures, the loudness of impact sound cannot be said to be entirely dependent on the sound energy of stimulus. The influence of peak sound pressure level (peak SPL) of stimulus is rather dominant. Under the same peak SPL condition, however, the PSE in- creases along with the increase in sound energy, which is caused by lengthening the stimulus duration and the rise of repetition rate. Accordingly the effect of the peak SPL and other factors concerned should be included in the method of evaluating loudness of impact sound.

In IEC 651, the "I" detector-indicator characteristic is specified for the measurement of impact sounds. Referring to our previous study ${ }^{2)}$ however, the characteristic "I" is not always adequate for the measurement of impact sounds, because it causes the overestimation of sound pressure level of an impact sound with rather long duration.

Then, here we propose a method for measuring the quantity here, which shows a good agreement with loudness of impact sound. An instrumentation for it may include a squaring circuit and an exponential averaging circuit with a certain time constant, and it can measure a steady sound in the same way as the sound level meter prescribed by JIS C 1502 


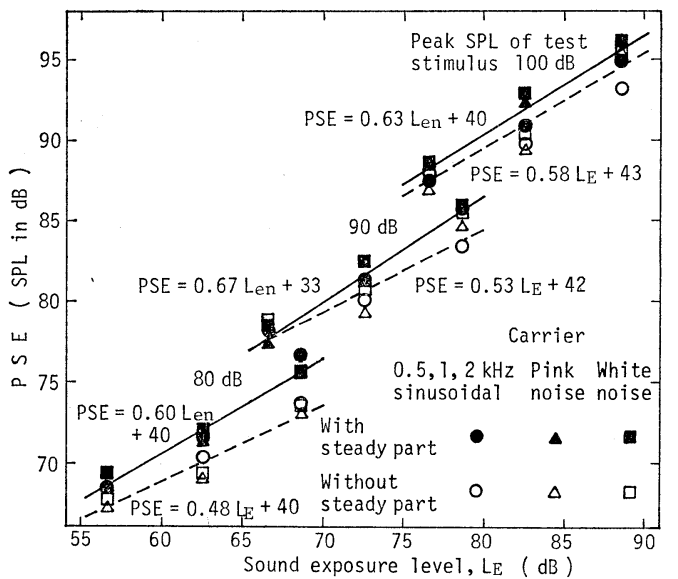

Fig. 1 Loudness of a single burst of impact sound.

Relation between calculated sound exposure level (not A-weighted) and PSE is shown here. The rise time and the decay time of test stimuli are $4 / 60,4 / 250$ or $4 /$ $1000 \mathrm{~ms}$ (without steady part), and the rise time, the steady duration and the decay time are $30 / 0.3 / 30,30 / 14 / 30$ or $30 / 68 / 30 \mathrm{~ms}$ (with steady part). Those of the comparison stimulus are $60 / 200 / 60 \mathrm{~ms}$. The rise time and the decay time are defined here as the time required for 60 $\mathrm{dB}$ change in sound pressure level.

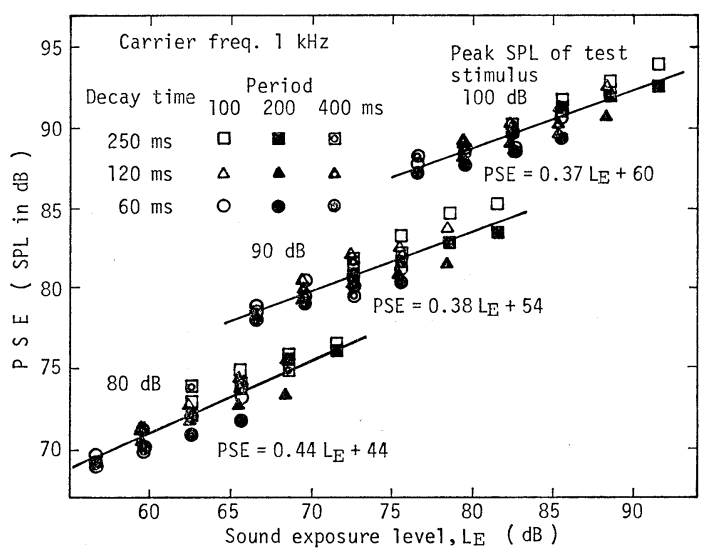

Fig. 2 Loudness of repeated impact sound. The rise time of each sound is $4 \mathrm{~ms}$, and its decay time is 60,120 or $250 \mathrm{~ms}$. Those sounds are presented repeatedly as test stimuli. The number of repetition is $1,2,4$ or 8 . (the Japanese Industrial Standards) does.

\section{EXPONENTIAL AVERAGING CIRCUIT OF A SOUND LEVEL METER FOR MEASURING AN IMPACT SOUND}

It is desirable that the impulse sound level meter is able to use not only for impact sound but also for steady sound as well without any modification or discrimination.

With reference to experimental results of a comparison of loudness of impact sound with that of quasi-steady sound, it can be said that PSE's for loudness of both sounds are nearly equal to each other in most cases as far as the sound pressure levels of those sounds measured through " $F$ " response circuit of a sound level meter indicate the same value. ${ }^{2)}$ The loudness of impact sound is underestimated in the case of a very short duration, if we adopt the value measured through " $F$ " response. This error is considered to be caused by the influence of steep onset of stimulus on neural activity, i.e. the firing rate of neural spikes increases in a stimulus with time duration shorter than a certain degree. ${ }^{2,3)}$ Some compensation should be contrived, therefore, in order to cover this area by the same method of measurement.

We indicate, hereafter, the sound pressure level estimated by an output of the exponential averaging circuit with $125 \mathrm{~ms}$ time constant by $S P L_{125}$, and that with $5 \mathrm{~ms}$ time constant by $S P L_{5}$. Table 1 shows the difference between $S P L_{5}$ and $S P L_{125}$ for each test stimulus shown in Fig. 1. As seen from the table, the difference is greater in the stimulus with shorter duration than in the stimulus with longer duration.

Table 1 Difference between $S P L_{5}$ and $S P L_{125}$ for each test stimulus appeared in Fig. 1.

\begin{tabular}{cccccc}
\hline & & $\begin{array}{c}\text { Rise } \\
\text { time } \\
(\mathrm{ms})\end{array}$ & $\begin{array}{c}\text { Steady } \\
\text { duration } \\
(\mathrm{ms})\end{array}$ & $\begin{array}{c}\text { Decay } \\
\text { time } \\
(\mathrm{ms})\end{array}$ & $\begin{array}{c}S P L_{5}-S P L_{125} \\
(\mathrm{~dB})\end{array}$ \\
\hline $\mathrm{I}$ & $\mathrm{T}$ & 4 & 0 & 60 & 10.4 \\
& $\mathrm{~S}$ & 30 & 0.3 & 30 & 11.1 \\
$\mathrm{II}$ & $\mathrm{T}$ & 4 & 0 & 250 & 7.7 \\
& $\mathrm{~S}$ & 30 & 14.0 & 30 & 8.6 \\
$\mathrm{III}$ & $\mathrm{T}$ & 4 & 0 & 1000 & 4.8 \\
& $\mathrm{~S}$ & 30 & 68.3 & 30 & 3.7 \\
\hline \multicolumn{6}{l}{ Comparison } \\
\hline
\end{tabular}




\section{KUMAGAI et al.: TIME CONSTANT FOR AN IMPULSE SOUND LEVEL METER}

We consider here the mean value of both $S P L$ 's as in the following equation ${ }^{2)}$ :

$$
S P L_{\mathrm{w}}{ }^{\prime}=\frac{S P L_{5}+S P L_{125}}{2}
$$

$S P L_{\mathrm{w}}{ }^{\prime}$ is about $5 \mathrm{~dB}$ larger than $S P L_{125}$ in the shorter stimuli, while the difference is only $2 \mathrm{~dB}$ in the longer stimuli. If we adopt $S P L_{\mathrm{w}}{ }^{\prime}$ as a measure of sound pressure level, the imperfection of $S P L_{125}$ for evaluating an impact sound with shorter duration can be compensated.

As $S P L_{\mathrm{w}}{ }^{\prime}$ is large by $3.9 \mathrm{~dB}$, on an average, than $S P L_{125}$, however, $S P L_{\mathrm{w}}$ of an impact sound calculated according to the following equation ${ }^{2)}$ may show a better correspondence with PSE including that for quasi-steady sound with $200 \mathrm{~ms}$ steady part:

$$
S P L_{\mathrm{w}}=\frac{S P L_{5}+S P L_{125}}{2}-4
$$

$S P L_{\mathrm{w}}$ has a few disadvantages, however, in actual measurement of impact sound, e.g. (1) measurements must be done two times, once for $S P L_{5}$ and once for $S P L_{125}$, and (2) a correction of $-4 \mathrm{~dB}$ must be added only for an impact sound. The latter brings an awkward situation, because a decision is required as to whether the sound is an impact or a steady one.

In order to solve these technical disadvantages, we describe a measuring system including two exponential averaging circuits with different time constants, by which an impact sound can be measured in the same way as a steady sound.

We will describe the situation here by using some kinds of sound pressure levels defined as follows:

$s p l_{T}(\mathrm{~dB})$ : the instantaneous sound pressure level through an exponential averaging circuit with a time constant $T \mathrm{~ms}$,

$s p l_{T_{1} / T_{2}}(\mathrm{~dB})$ : the instantaneous sound pressure level through an exponential averaging circuit with a rise time constant $T_{1} \mathrm{~ms}$ and a decay time constant $T_{2} \mathrm{~ms}$,

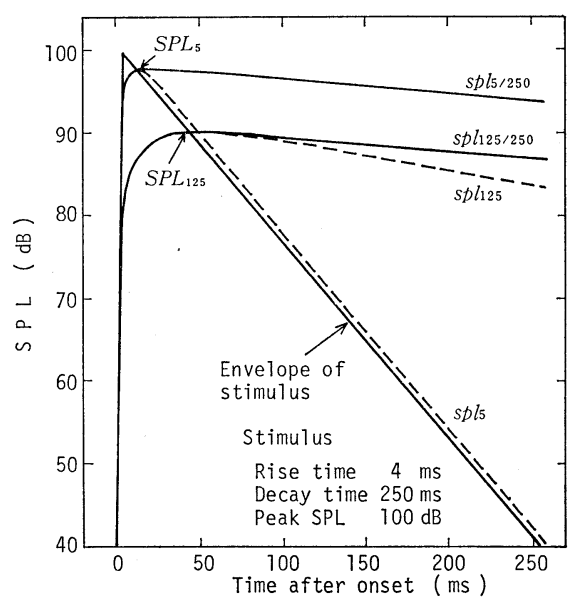

Fig. 3 The instantaneous sound pressure levels indicated through several kinds of exponential averaging circuits.

$S P L_{T}(\mathrm{~dB}):$ the maximum value of $s p l_{T}$, and $S P L_{T_{1} / T_{2}}(\mathrm{~dB})$ : the maximum value of $s p l_{T_{1 / T_{2}}}$.

Figure 3 shows the examples of temporal change of $s p l_{5}, s p l_{125}, s p l_{5 / 250}$ and $s p l_{125 / 250}$. The curves in this figure show calculated value for the impact sound with $100 \mathrm{~dB}$ peak sound pressure level, $4 \mathrm{~ms}$ rise time and $250 \mathrm{~ms}$ decay time. As is clearly shown in Fig. 3,

$$
S P L_{5}+S P L_{125} \neq\left[s p l_{5}+s p l_{125}\right]_{\max }
$$

and

$$
S P L_{5}+S P L_{125} \fallingdotseq\left[s p l_{5 / 250}+s p l_{125 / 250}\right]_{\max }
$$

The decay time constant of $250 \mathrm{~ms}$ was chosen from the experimental result for loudness of repeated impact sound. ${ }^{4)}$ From these relations the maximum value of the sum of $s p l_{5 / 250}$ and $s p l_{125 / 250}$ obtained from a single measurement is a satisfactory measure in place of the sum of $S P L_{5}$ and $S P L_{125}$ obtained from two measurements.

Figure 4 is a block diagram of a measuring system to realize the idea mentioned above. In this figure,

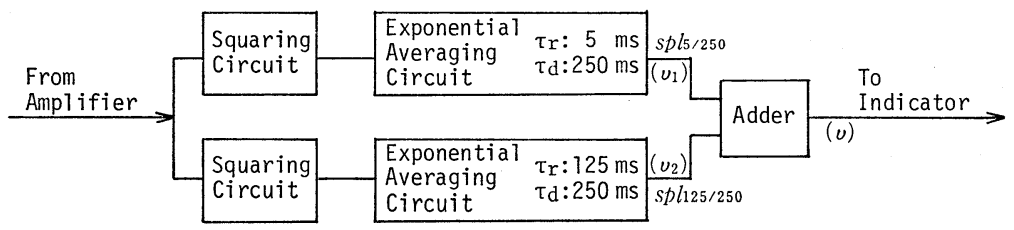

Fig. 4 A block diagram of a basic part of the measuring system for both impact and steady sounds. 


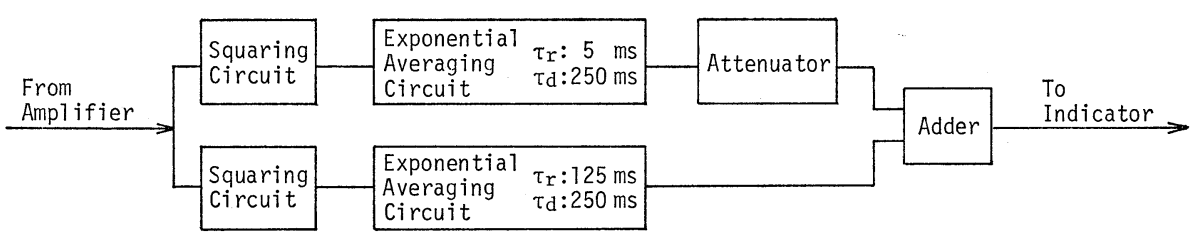

Fig. 5 A block diagram of a revised measuring system for both impact and steady sounds.

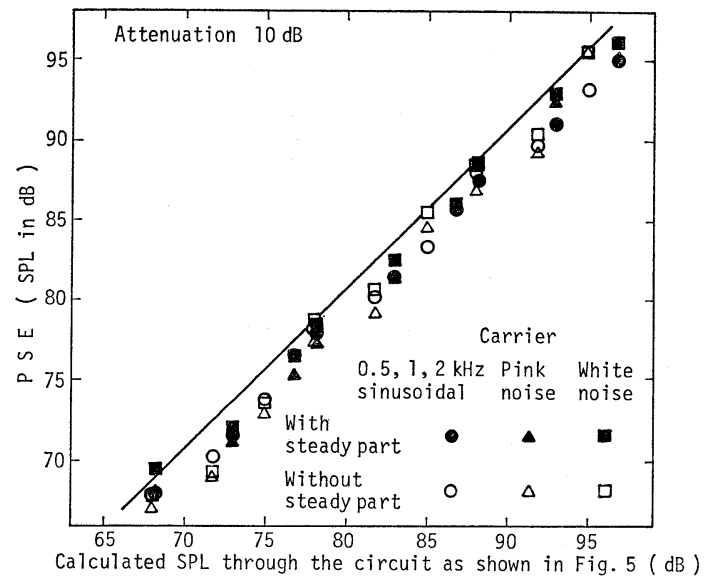

Fig. 6 Loudness of a single burst of impact sound.

Relation between calculated SPL, where the attenuation for $s p l_{5 / 250}$ is $10 \mathrm{~dB}$, and the PSE is shown here. SPL is calculated for the system as shown in Fig. 5, and PSE is taken from the experimental result shown in Fig. 1. The solid line in this figure denotes the estimated PSE for quasisteady sound with $200 \mathrm{~ms}$ steady duration.

the outputs of the exponential averaging circuits, $v_{1}$ and $v_{2}$, are not proportional to sound pressure levels. These $v_{1}$ and $v_{2}$ are expressed by

$$
\nu_{1}=10^{\left(s p l_{5 / 250}\right) / 10}, \quad \nu_{2}=10^{\left(s p l_{125 / 250}\right) / 10}
$$

and then the sum of $v_{1}$ and $v_{2}$ is

$$
\nu=10^{\left(s p l_{5 / 250}\right) / 10}+10^{\left(s p l_{125 / 250}\right) / 10}
$$

This is not an arithmetic summation but a power summation.

The principal purpose of adding $S P L_{5}$ to $S P L_{125}$ is to modify $S P L_{125}$ to agree with a sensation caused by a short sound. For a sound with long duration, $S P L_{5}$ has no effect on the value of $S P L_{125}$. This modification which makes use of the change in difference between $S P L_{5}$ and $S P L_{125}$ caused by the duration of sound is available in a power-summation

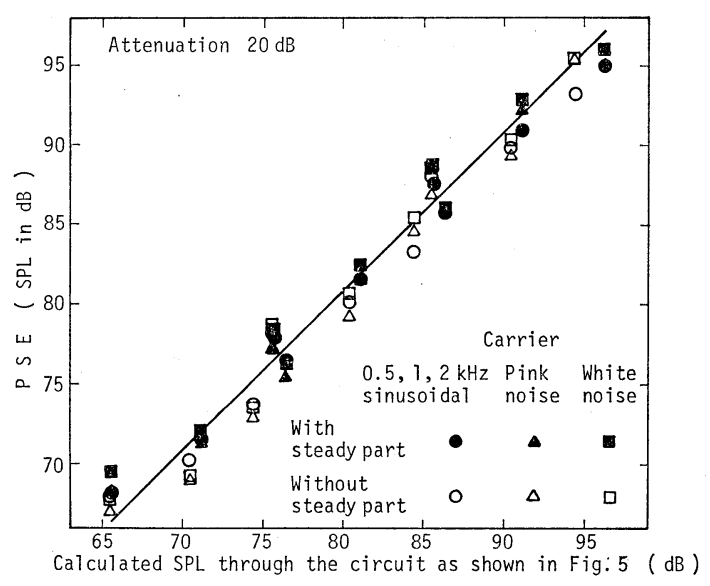

Fig. 7 The same relation as in Fig. 6 except that the attenuation for $s p l_{5 / 250}$ is $20 \mathrm{~dB}$.

system as shown in Fig. 4.

As seen from Fig. 3, however, $s p l_{5 / 250}$ is always greater than $s p l_{125 / 250}$. The difference between these two levels attains $10 \mathrm{~dB}$ for the stimulus with very short duration, so that the output voltage from the adder circuit is mainly determined by $s p l_{5 / 250}$. This does not suit our purpose. Then the magnitude of $s p l_{5 / 250}$ must be attenuated before feeding it to the adder circuit as shown in Fig. 5.

Figure 6 shows the relation between the resultant SPL and PSE, where the SPL is calculated on the assumption that the attenuation for $s p l_{5 / 250}$ is $10 \mathrm{~dB}$ and PSE is taken from the experimental results shown in Fig. 1.

Figure 7 shows the same relation as in Fig. 6 except that the attenuation for $s p l_{5 / 250}$ is $20 \mathrm{~dB}$. The solid lines in both figures denote the estimated PSE for quasi-steady sound with $200 \mathrm{~ms}$ steady part.

It is desirable for us to evaluate the loudness of both impact and steady sounds by the same method using such a sound level meter as mentioned above. 


\section{KUMAGAI et al.: TIME CONSTANT FOR AN IMPULSE SOUND LEVEL METER}

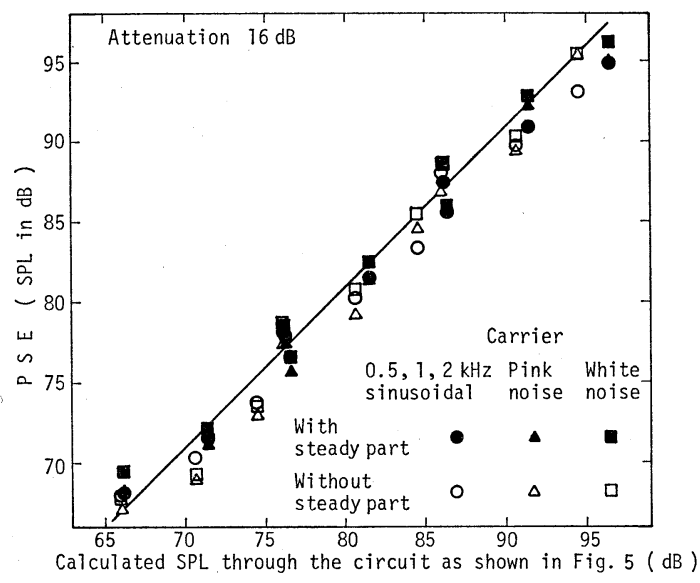

Fig. 8 The same relation as in Fig. 6 except that the attenuation for $s p l_{5 / 250}$ is $16 \mathrm{~dB}$. This attenuation of $16 \mathrm{~dB}$ is the optimum value to minimize the deviation of measured SPL of impact sound from that of quasi-steady sound.

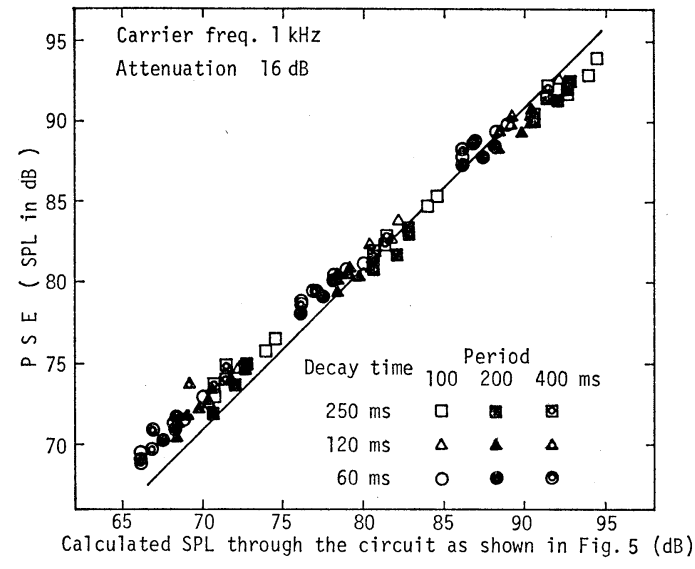

Fig. 9 Loudness of repeated impact sound. The attenuation for $s p l_{5 / 250}$ is $16 \mathrm{~dB}$, which is found to be optimum as seen in Fig. 8. PSE is an experimental result taken from Fig. 2. Other conditions are the same as in Fig. 6.

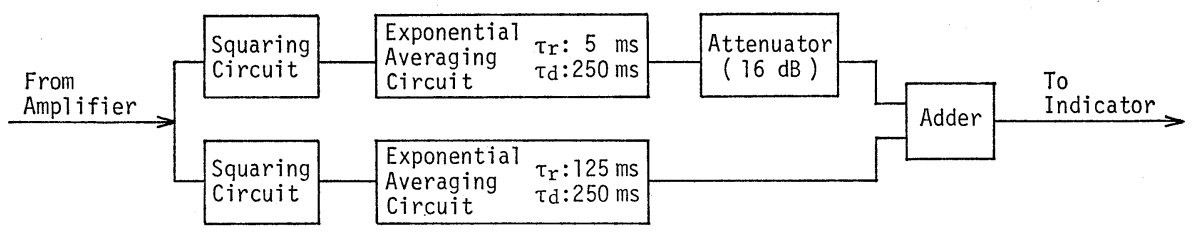

Fig. 10 The block diagram of a final system for measuring both impact and steady sounds.

If the PSE for loudness of impact sound and that of steady sound are equal, therefore, the measured SPL of impact sound is required to be equal to the measured SPL of steady sound. The optimum attenuation for $s p l_{5 / 250}$ to minimize the deviation of SPL of impact sound from that of quasi-steady sound, which has the same PSE as the former, is found to be $16 \mathrm{~dB}$.

Figure 8 shows the same relation as in Fig. 6 except that the attenuation of $16 \mathrm{~dB}$, the optimum attenuation, is adopted here. Figure 9 shows the relation between SPL and PSE for loudness of repeated impact sound, where PSE is the values taken from the experimental results in Fig. 2. The solid line is the same as in Fig. 6. From this figure, it can be said that the method of measuring SPL through $16 \mathrm{~dB}$ attenuation is appropriate for the evaluation of the loudness of repeated impact sound as well as a single burst of impact sound.

The quasi-steady sound with duration of $200 \mathrm{~ms}$ is treated as steady sound in our discussion on the comparison of loudness of impact sound with steady sound, the quasi-steady sound with a duration of $200 \mathrm{~ms}$ is regarded as the steady sound, referring to the literatures concerning the critical duration of sound from a point of loudness.

\section{CONCLUSION}

A sound level meter with a circuit as shown in Fig. 10 indicates the SPL value which corresponds well to the loudness of both impact and steady sounds. The remaining part of this sound level meter is just the same as the usual sound level meter.

The SPL of impact sound measured by this sound level meter, whether it is a single burst or a repeated impact sound, shows nearly the same SPL as steady sound which has a loudness equal to the impact sound. This sound level meter is useful for evaluating the loudness of impact sound and steady 
sound by the same method.

Furthermore, the difference of SPL between a quasi-steady sound with duration of $200 \mathrm{~ms}$ and a steady sound is about $1.0 \mathrm{~dB}$ on the sound level meter mentioned here, and so it meets the requirement of the IEC Standard, Pub. 651 "F" Type 1, 2 and 3.

\section{REFERENCES}

1) M. Kumagai, M. Ebata, and T. Sone, "Effect of some physical parameters of impact sound on its loudness (A study on the loudness of impact sound. I)," J. Acoust. Soc. Jpn. (E) 2, 15-26 (1981).
2) M. Kumagai, M. Ebata, and T. Sone, "Comparison of loudness of impact sounds with and without steady duration (A study on the loudness of impact sound. II)," J. Acoust. Soc. Jpn. (E) 3, 33-40 (1982).

3) M. Kumagai, M. Ebata, and T. Sone, "Loudness of impact sound with wide-band spectrum (A study on the loudness of impact sound. III)," J. Acoust. Soc. Jpn. (E) 3, 111-118 (1982).

4) M. Kumagai, Y. Suzuki, and T. Sone, "The loudness of repeated impact sound (A study on the loudness of impact sound. IV)," J. Acoust. Soc. Jpn. (E) 3, 231-237 (1982). 